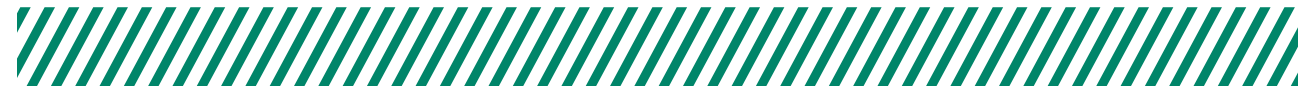

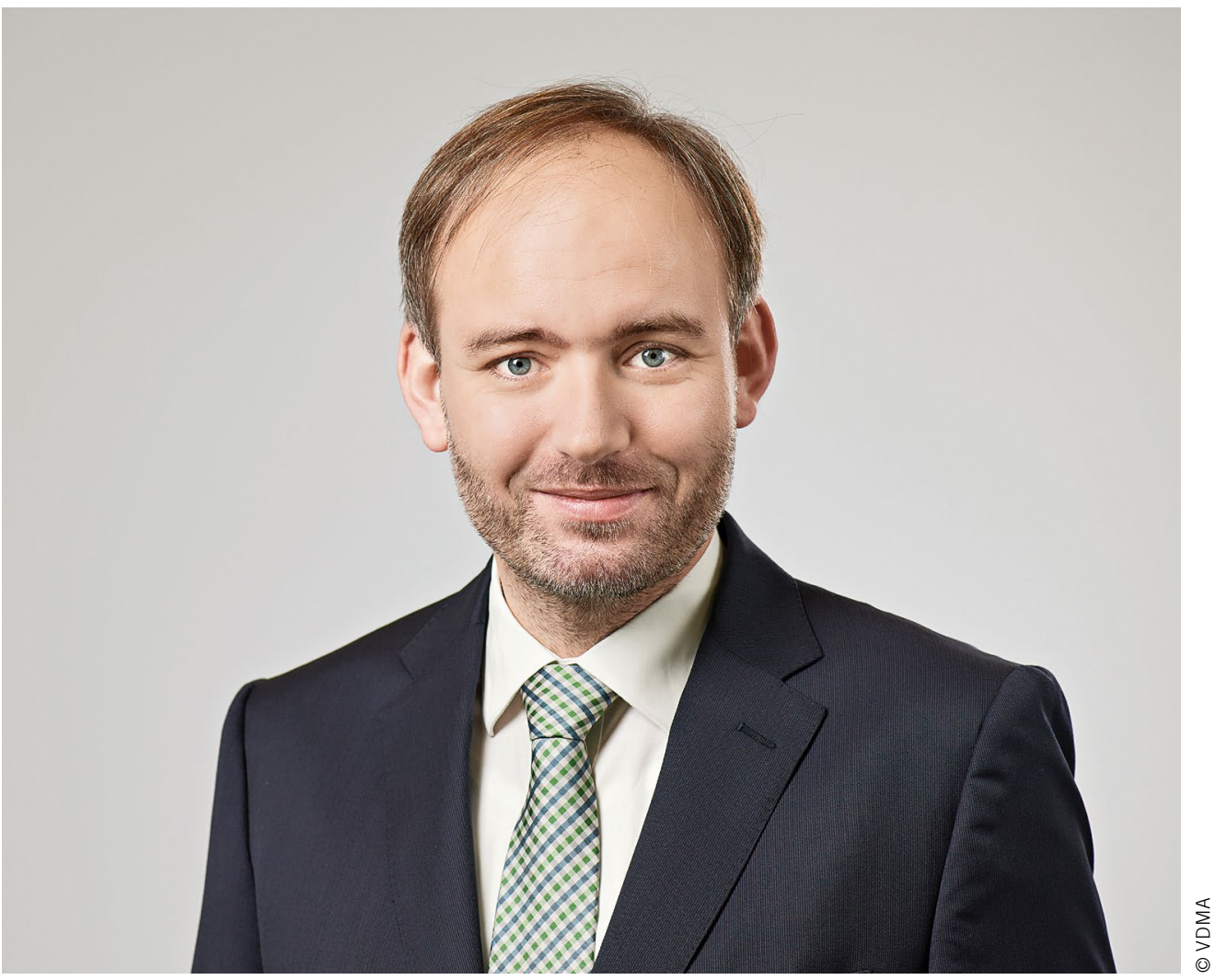

Alexander Raßmann

Project Manager Forum \#XMotive of VDMA e. V. in Frankfurt am Main (Germany)

\section{Technological Diversity for Mobility}

Even during the coronavirus pandemic, which is currently dominating the public debate, the need to achieve the climate goals of the Paris Declaration has not lost its importance. The goals have top priority. One important cornerstone for this, among many others, is the mobility sector - on and off the road. The change is underway, hybrid and fully electric vehicles are increasingly becoming the standard.

In contrast to passenger cars - where the trend toward battery-electric vehicles seems to prevail - the requirements in the field of commercial vehicles and mobile machinery are different and much more diverse. In the long term, climate neutrality for these vehicles and machines can only be achieved with a mix of various technologies. In each case, the best technology for the respective application must be identified. Regardless of the used energy source, it must be based on regeneratively produced electricity.

The decision over drive systems for commercial vehicles and mobile machinery is mainly driven by the Total Cost of Ownership (TCO). The study series Drivetrain in Transition, conducted by the VDMA together with FEV Consulting, provides important insights in to this topic. An important factor is the legislation and its definition of emission targets. Particularly in the case of heavy commercial vehicles, the utility profile will have a direct impact on the drive system. While light batteryelectric commercial vehicles with defined driving profiles already show a positive TCO, heavy commercial vehicles with their high power throughput will tend to use technologies that enable a long range and fast refueling. Purely electric applications are only of limited use in this field due to the size and weight of the necessary batteries. The fuel cell will play an important role in heavy-duty transportation with relevant unit numbers in Europe even before 2030. Therefore, heavy-duty transport is an important driver for the development of a hydrogen infrastructure. Synthetic fuels are also expected to make an important contribution to climate neutrality.

For each technology that guarantees mobility in the future, the mechanical engineering industry will be crucial as an innovative provider for solutions - be it in hybrid and electric drives, lightweight design, battery production or the generation of fuels from green energy. After all, manufacturing is the key to an economically and ecologically sustainable mobility in the future. The industries of mechanical engineering and plant engineering will play a leading role in the transformation of mobility systems. 